\title{
Consequences of Low Risk and Hazardous Alcohol Consumption among University Students in Australia and Implications for Health Promotion Interventions
}

\author{
Sharyn Burns ${ }^{1}$, Gemma Crawford ${ }^{1}$, Jonathan Hallett ${ }^{1}$, Jonine Jancey ${ }^{1}$, Linda Portsmouth ${ }^{1}$, \\ Kristen Hunt ${ }^{1}$, Janelle Longo ${ }^{2}$ \\ ${ }^{1}$ School of Public Health, Curtin University, Perth, Australia \\ ${ }^{2}$ South Metropolitan Population Health Unit, Department of Health, Fremantle, Australia \\ Email: s.burns@curtin.edu.au
}

Received 19 December 2014; accepted 31 December 2014; published 14 January 2015

Academic Editor: Maciej Buchowski, Vanderbilt University Medical Center, USA

Copyright (C) 2015 by authors and Scientific Research Publishing Inc.

This work is licensed under the Creative Commons Attribution International License (CC BY). http://creativecommons.org/licenses/by/4.0/

c. (i) Open Access

\section{Abstract}

Background: Hazardous alcohol consumption and associated harms are high among young university students. The university environment is conducive to excessive alcohol consumption with studies finding young university students to drink alcohol at higher levels than their non-university peers. Methods: A random sample of 18 - 24-year-old undergraduate, internal university students completed a survey $(n=2465)$ to investigate differences in self-reported personal, secondhand and witnessed alcohol-related harms, alcohol expectancies, pre-loading, and friends' alcohol consumption between low risk and hazardous drinkers. Univariate and multivariate analyses are reported. Results: Almost $\mathbf{4 0 \%}$ of students who had consumed alcohol in the past year reported drinking at hazardous levels. Univariate analyses found students who reported hazardous drinking reported significantly higher scores relating to experienced, second-hand, witnessed and academic problems compared to low risk drinkers. Hazardous drinkers were also more likely to pre-load, to drink at higher levels when pre-loading, have more friends who drank alcohol, have more friends who drank at hazardous levels and to score higher on alcohol expectancies. However both low risk and hazardous drinkers experienced a range of harms due to their own drinking including hangover (71.2\%), unprotected sex $(19.3 \%)$, regretted sex $(16.8 \%)$ and drink-driving (17\%). Looking after an intoxicated student $(34.3 \%)$ and witnessing someone pass out (37.5\%) were issues for all drinkers. Experienced alcohol related harms, academic problems, alcohol expectancies, close friends' level of alcohol consumption, pre-loading in the last four weeks and level of consumption when pre-loading were predictors of hazardous drinking ( $p<$

How to cite this paper: Burns, S., Crawford, G., Hallett, J., Jancey, J., Portsmouth, L., Hunt, K. and Longo, J. (2015) Consequences of Low Risk and Hazardous Alcohol Consumption among University Students in Australia and Implications for Health Promotion Interventions. Open Journal of Preventive Medicine, 5, 1-13.

http://dx.doi.org/10.4236/ojpm.2015.51001 
0.001). Conclusion: Young undergraduate university students are at risk of a range of academic, social, emotional and physical harms associated with their own and other students' alcohol consumption. There is a need for integrated programs to address university drinking culture and effect positive changes.

\section{Keywords}

\section{Alcohol, University Student, Hazardous Consumption, Harms, Expectancies}

\section{Introduction}

University students in many developed countries [1]-[3], report high levels of hazardous alcohol consumption. Comparisons demonstrate that university students drink at more hazardous levels than their non-university based peers [1]. While it has been suggested this behavior is associated with "rites of passage" [4], there is evidence that this short period of excessive drinking can have serious long term implications, as well as a range of short term harms [1]. Young university students experience harms associated with their own alcohol consumption as well as a result of the alcohol consumption of others [5] [6]. Students have reported personal harms such as hangovers, blackouts, injury, regretted sexual activity and academic impairment as well as harms to others including interpersonal and sexual violence. Risky behaviors such as damage to property and drink driving are also common alcohol-related consequences [7] [8]. Second-hand harms as a result of other students' alcohol consumption are also of concern and include being involved in an argument, interpersonal or sexual violence, having study or sleep interrupted, becoming a victim of crime and looking after others who are intoxicated [5].

Availability and promotion of alcohol, events that encourage excessive drinking, students living away from home for the first time, new peer networks and university policy that does not discourage excessive drinking have contributed to a culture of drinking among young university students [1]. Such culture is influenced by alcohol expectancies which have been found to influence social and cultural norms towards alcohol consumption [9] [10]. The homogeneity of peers also plays an important role in behavior and in the formation of social norms associated with alcohol consumption [11] [12].

Hazardous alcohol consumption among university students has been demonstrated over the past 15 years, [1] [3] [13] [14] leading to a range of brief interventions, many of which demonstrate promising short term results. A systematic review of 18 brief interventions focusing on face-to-face motivational interviewing targeting US college students engaged in heavy episodic drinking found reductions in alcohol consumption after 12 months [15]. In Australia [2] and New Zealand [16], web based screening and brief intervention for university students have demonstrated short term change. One New Zealand study found a reduction in alcohol consumption, Alcohol Use Disorders Identification Test (AUDIT)scores [17] and academic problems after 12 months [16]. A similar intervention in Australia found a reduction in volume and frequency of alcohol consumed after six months [2]. However a UK web-based personalized normative feedback intervention using the same measures as the Australian and New Zealand studies found no significant reduction in levels of alcohol consumption or alcohol-related problems at six or twelve months [18].

However despite strong evidence of hazardous drinking among university students, [1] [3] [13] [14] some evidence of short term success for brief interventions [2] and the success of integrated interventions targeting other health issues, [19] [20] there is a dearth of peer reviewed comprehensive interventions targeting alcohol consumption and related issues among young university students. Evidenced based health promotion [21] and alcohol prevention [22] suggest comprehensive multi-faceted interventions, especially those which address policy and structural change, are most likely to have long term impact.

This paper compares key variables for low risk and hazardous drinkers from a random cross sectional sample of 18 - 24-year-old university students. Findings will be used to inform the development of an integrated and comprehensive intervention at a large and culturally diverse university campus with the aim of reducing witnessed and experienced harms associated with alcohol consumption among young students. Building on research that explores alcohol-related harms, [3] [23] [24] this paper will explore the influence of alcohol expectancies, friends' alcohol consumption and behaviors on level of drinking. 


\section{Method}

\subsection{Study Design and Procedure}

The current study used methods consistent with those previously conducted at this university [23] [25]. Participants were drawn from a random cross-sectional sample of 6000,undergraduate, internally enrolled students, aged 18 - 24 years, studying at the main metropolitan campus of a large Australian university. An invitation was sent to their student email address inviting them to participate in the baseline online questionnaire by the University Surveys Office. Emails were sent coinciding with the release of semester one results to increase the likelihood students would access their email. Two follow up emails were sent after the initial invitation to participate. Responses were received from 1930 students (32.2\% response rate). A further 628 students were randomly recruited via intercept survey during campus market day. Data were collected by trained research assistants. Consent was provided through completion of the survey. All data were collected in July-August 2013. The total sample was 2588, of these 2465 completed the survey. This study was approved by the Curtin University Human Ethics Committee (Approval No. HR 54/2013).

\subsection{Instrumentation}

Demographic data included age, gender, faculty of enrolment (Business, Engineering and Science, Health Science or Humanities or Centre for Aboriginal Studies) and place of residence while at university (living in a shared house, with a parent or guardian, as a boarder or alone or with partner/children).

Respondents completed the 10 item AUDIT which provides a measure of alcohol-related harm, levels of hazardous consumption and possible dependence [17]. Consistent with the analysis of AUDIT, scores were initially computed into four ordinal categories: low risk (0 - 7); hazardous (7 - 15); harmful (16 - 19) and high risk (20 and over) then computed for the binary categories of low risk (non-hazardous; $<8$ ) and hazardous (risky; $\geq 8$ ) drinking [17] [23].

The Academic Role Expectations and Alcohol Scale (AREAS) [26] were used to measure academic problems. This study included four items and asked students to report the numbers of times they had been late for a class, missed a class, were unable to concentrate in class or failed to complete an assignment on time. Students were asked to respond with not at all, once, twice, three times, or four or more times [score range 0 - 16]. This item had a twelve month reference period.

The Alcohol Problems Scale (APS) [23] [26] included 17 items of harms experienced in the 12 months preceding the survey as a result of personal alcohol consumption. Students were asked to respond with yes, no or prefer not to answer [score range 0 - 17]. Second-hand harm was measured using a scale comprising 11 items of harms experienced as a result of other student's alcohol consumption [6] [26]. An additional scale was developed to include six harms that students had witnessed as a result of other students' alcohol consumption. Students were asked to respond with never, once, twice, three times, or four of more times for second-hand [score range 0 - 44] and witnessed harms [score range 0 - 24]. These items had a four week reference period.

Expectancies towards alcohol consumption were measured using nine items from the Brief Comprehensive Effects of Alcohol Scale (B-CEOA) [9]. Students were asked to rate the extent to which they believed a few drinks of alcohol would influence socialization, risk and aggression, sexuality, self-perception and tension reduction and were asked to respond with agree, neither agree or disagree or disagree [score range 9 - 27].

Two questions were asked to measure pre-loading (pre-drinking, pre/gaming, pre-partying). Consistent with Australian terminology students were asked to consider their pre-drinking/pre-loading behavior associated with consumption of alcohol before an event/social activity. The first referred to a four week reference period and asked students if they had ever pre-loaded. Students were asked to respond with never, once or twice, three or four times or five or more times. A subsequent question asked students to report the number of standard drinks consumed on the last time they pre-loaded. Five levels of consumption were provided ranging from one to two drinks to 10 or more drinks at their last pre-loading event. To measure the proportion of friends who regularly drink alcohol five possible responses were provided ranging from "none" to "all of my friends" [27]. An estimate of close friends' level of alcohol consumption was measured by asking students to estimate the average number of standard drinks consumed by close friends when drinking [28].

The final questionnaire was tested for face validity with a sample of the target group $(n=10)$ and for content validity using an expert panel of health promotion and alcohol prevention experts $(n=8)$. 


\subsection{Data Analysis}

The dependent variable for this analysis was the AUDIT score which was collapsed to a binary variable to determine low risk and hazardous drinking. Statistical significance and proportions were compared for categorical variables using Chi-Square analyses. Means were compared for continuous factors. Analysis of Variance (ANOVA) was used to evaluate statistical differences. Odds ratios were used to estimate the relative risk of low risk or hazardous drinking and key variables. $\mathrm{p}$-values of $\mathrm{p}<0.001$ and $\mathrm{p}<0.05$ were chosen to discern highly and moderately significant differences respectively [29].

Binary logistic regression was used to test for associations between exploratory variables and low risk and hazardous drinking (AUDIT). Demographic variables included gender (due to low numbers of "other" gender male/female only were used for this analysis), age, faculty of enrolment and place of residence. Independent variables included experienced harms (associated with own drinking), academic problems (associated with own drinking), witnessed harms (associated with drinking of another), second-hand harms (associated with drinking of another), alcohol expectancies, preloading experience, pre-loading consumption levels, proportion of friends drinking and level of close friends alcohol consumption. All variables (Table 1) were initially entered into the model. Non-significant variables were removed one at a time, to create a more parsimonious model. Data were analyzed using SPSS for Windows version 21.0.

\section{Results}

Data were collected for 2465 students. Of these 37.6\% ( $\mathrm{n}=926)$ were male, $62.1 \%(\mathrm{n}=1531)$ female and $0.3 \%$ $(n=8)$ other gender (queer $n=3$; androgynous $n=1$; intersex $n=1$, not identified $n=1$ ). There was a similar mix of younger (18 - 20 years; 48.7\%) compared to older students (21 - 24; 51.3\%). The majority of respondents reported to live with parent/s or guardian/s (63.3\%), followed by sharing a flat or residence (23.5\%); living with partner and or children (4.8\%) or living in student housing (4.4\%). The remainder lived alone or boarded. Students from the Faculty of Health Science were most likely to participate in this study (37.2\%).

The majority of students $(\mathrm{n}=2061 ; 89.1 \%)$ in this study reported they had consumed alcohol in the last 12 months. Of the students who completed the AUDIT questions, the majority were categorised as low risk $(\mathrm{n}=$ 1230; 60.3\%); followed by risky $(n=665 ; 32.6)$; harmful $(n=90 ; 4.4 \%)$; and high risk $(2.7 \%$; $n=56)$. When binary variables were created $39.7 \%(n=811)$ reported they drank at risky/hazardous or higher levels (score of $\geq 8$ ) and were categorised as hazardous drinkers.

Table 1 shows the results of the initial univariate analysis comparing low risk and hazardous drinking to key demographic and independent variables. Males were more likely to participate in hazardous drinking (46.9\%) compared to females (35.2\%). There was no significant difference between low risk or hazardous drinking and age, faculty of enrolment or place of residence when univariate analyses were conducted.

Students who reported hazardous drinking reported significantly higher experienced harm scores (M 5.66; SD 3.08); second-hand harm (M 3.22; SD 4.66); witnessed harm (M 3.14; SD 4.10), academic problems (M2.55; SD 3.57) and alcohol expectancies (M 23.31; SD 2.92) scores compared to low risk drinkers (Table 1).

Most (85.2\%) hazardous drinkers reported pre-loading (pre-drinking) at least once during the last four weeks with 55.8\% reporting to drink five or more standard drinks during their last pre-loading episode. Hazardous drinkers were significantly more likely to pre-load and to drink at higher levels when pre-loading compared to low risk drinkers $(\mathrm{p}<0.001)$. Almost all low risk and hazardous drinkers reported having at least a few friends who drink regularly (low $97.7 \%$ vs high $99.5 \%$ ) however hazardous drinkers were significantly more likely to have a greater proportion of close friends who drink regularly (most: $54.6 \%$ vs $36.2 \%$ ) and to have close friends who drink at least five drinks when drinking compared to low risk drinkers (78.3\% vs 32.6\%; $p<0.001)$ (Table $1)$.

Table 2 shows the results of univariate analyses of the key items for experienced, second-hand and witnessed harms, academic problems and alcohol expectancies for low risk and hazardous drinkers. There was a significant difference $(\mathrm{p}<0.001)$ between low risk and hazardous drinkers for all harms experienced as a result of the respondents own alcohol consumption in the past twelve months (apart from "being arrested" which had a low incidence for both groups). Almost all participants who reported hazardous drinking had experienced a hangover (91.5\%). Commonly experienced harms for hazardous drinkers were: blackouts (71.1\%); unprotected sex (34.5\%); emotional outburst (57.3\%); heated argument (39.5\%); vomiting, (73.3\%) and being physically aggressive (20.3\%). Other harms experienced significantly more often for hazardous drinkers were: a sexual encounter 
Table 1. Predictors of hazardous and low risk drinking using univariate analysis.

\begin{tabular}{|c|c|c|c|c|}
\hline Demographics & Low risk N (\%) & Hazardous N (\%) & Total N (\%) & $p$ value \\
\hline Gender & & & & $0.000^{*}$ \\
\hline Male & $407(53.1)$ & 359 (46.9) & $766(37.5)$ & \\
\hline Female & $823(64.8)$ & $447(35.2)$ & $1270(62.3)$ & \\
\hline Other & 0 & $4(100)$ & $4(0.2)$ & \\
\hline Total & $1230(60.3)$ & $810(39.7)$ & 2040 & \\
\hline Age & & & & 0.528 \\
\hline 18 - 20 years & $606(61)$ & 388 (39) & $994(48.7)$ & \\
\hline $21-24$ years & $624(59.6)$ & $423(40.4)$ & $1047(51.3)$ & \\
\hline Total & $1230(60.3)$ & 811 (39.7) & 2041 & \\
\hline Faculty & & & & 0.285 \\
\hline Health science & $474(61.5)$ & 297 (38.5) & $771(37.2)$ & \\
\hline Science and engineering & $262(58)$ & $190(42)$ & $452(22.4)$ & \\
\hline Humanities & $246(58.6)$ & $174(41.4)$ & $420(20)$ & \\
\hline Business & 247 (62.7) & $147(37.3)$ & $394(20.1)$ & \\
\hline Aboriginal studies & $1(25)$ & $3(75)$ & $4(0.2)$ & \\
\hline Total & $1230(60.3)$ & $811(39.7)$ & 2041 & \\
\hline Place of residence while at university & & & & 0.279 \\
\hline Share flat/house & $275(58)$ & $199(42)$ & $474(23.2)$ & \\
\hline Student housing & $57(63.3)$ & 33 (36.7) & $90(4.4)$ & \\
\hline Parent/guardian & $786(60.6)$ & $510(39.4)$ & $1296(63.5)$ & \\
\hline Live alone & $21(68.4)$ & $12(34.6)$ & $33(1.6)$ & \\
\hline With partner/children & $67(68.4)$ & $31(31.6)$ & $98(4.8)$ & \\
\hline Board/live with other relative or friend/other & $24(48)$ & $26(52)$ & $50(2.5)$ & \\
\hline Total & $1230(60.3)$ & $811(39.7)$ & 2041 & \\
\hline \multicolumn{5}{|l|}{ Independent variables } \\
\hline $\begin{array}{l}\text { Experienced harm } \\
\quad(\mathrm{n}=1995)\end{array}$ & $\begin{array}{c}\text { M2.453 } \\
\text { SD } 2.453 \\
\text { CI } 2.079-2.357\end{array}$ & $\begin{array}{c}\text { M 5.6662 } \\
\text { SD 3.088 } \\
\text { CI } 5.451-5.881\end{array}$ & $\begin{array}{c}\text { M } 3.596 \\
\text { SD } 3.20 \\
\text { CI } 4.455-3.736\end{array}$ & $0.000 *$ \\
\hline $\begin{array}{l}\text { Second-hand harm } \\
\qquad(\mathrm{n}=2013)\end{array}$ & $\begin{array}{c}\text { M } 1.305 \\
\text { SD } 2.550 \\
\text { CI } 1.61-1.44\end{array}$ & $\begin{array}{c}\text { M } 3.221 \\
\text { SD } 4.660 \\
\text { CI } 2.89-3.54\end{array}$ & $\begin{array}{c}\text { M } 2.070 \\
\text { SD } 3.668 \\
\text { CI } 1.919-2.231\end{array}$ & $0.000^{*}$ \\
\hline $\begin{array}{l}\text { Witnessed harm } \\
\qquad(\mathrm{n}=2013)\end{array}$ & $\begin{array}{c}\text { M } 1.476 \\
\text { SD } 2.841 \\
\text { CI } 1.316-1.636\end{array}$ & $\begin{array}{c}\text { M } 3.148 \\
\text { SD } 4.101 \\
\text { CI } 2.864-3.431\end{array}$ & $\begin{array}{c}\text { M } 2.144 \\
\text { SD } 3.497 \\
\text { CI } 1.992-2.296\end{array}$ & $0.000^{*}$ \\
\hline $\begin{array}{l}\text { Academic problems } \\
\qquad(\mathrm{n}=1995)\end{array}$ & $\begin{array}{c}\text { M } 0.4891 \\
\text { SD } 1.454 \\
\text { CI } 0.406-0.571\end{array}$ & $\begin{array}{c}\text { M } 2.555 \\
\text { SD } 3.578 \\
\text { CI } 2.307-2.804\end{array}$ & $\begin{array}{c}\text { M } 1.314 \\
\text { SD 2.721 } \\
\text { CI } 1.195-1.434\end{array}$ & $0.000^{*}$ \\
\hline $\begin{array}{l}\text { Alcohol expectancies } \\
\quad(\mathrm{n}=2041)\end{array}$ & $\begin{array}{c}\text { M 21.110 } \\
\text { SD 3.669 } \\
\text { CI } 20.905-21.315\end{array}$ & $\begin{array}{c}\text { M } 23.312 \\
\text { SD } 2.920 \\
\text { CI } 23.110-23.513\end{array}$ & $\begin{array}{c}\text { M } 21.985 \\
\text { SD } 3.558 \\
\text { CI } 21.830-22.139\end{array}$ & $0.000^{*}$ \\
\hline $\begin{array}{l}\text { Friends who drink regularly } \\
\qquad(\mathrm{n}=1982)\end{array}$ & & & & $0.000^{*}$ \\
\hline None & $34(2.9)$ & $4(0.5)$ & 38 (1.9) & \\
\hline
\end{tabular}




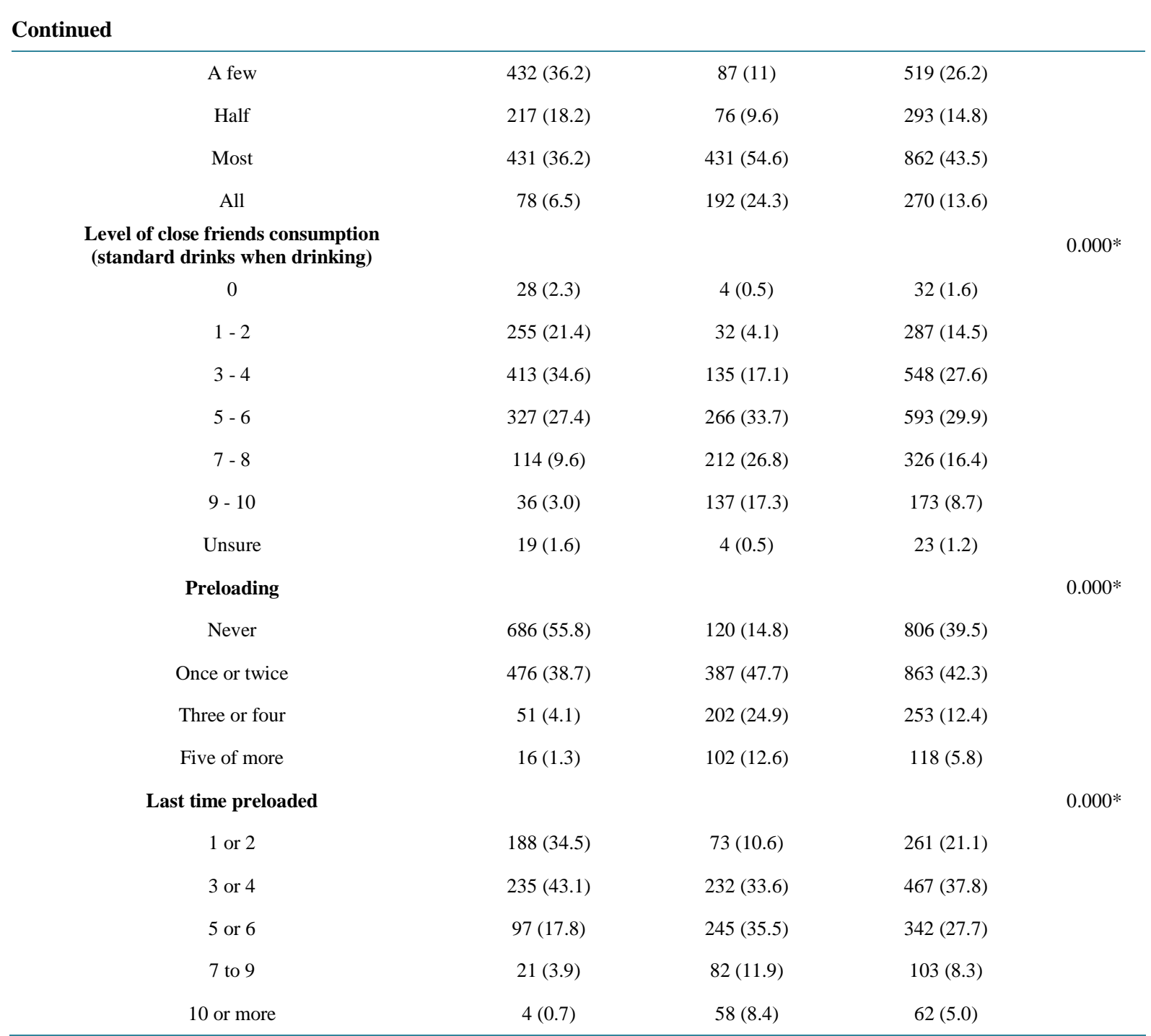

Significant at $\mathrm{p}<0.001^{*}$.

which was later regretted (29.7\%); drink -driving (28.7\%); or drink-riding (being a passenger in a car when the driver had too much to drink) (39.9\%) (Table 2).

Compared to low risk drinkers, hazardous drinkers were significantly more likely to experience academic harms as a result of their own alcohol consumption in the last twelve months including being late for a class (30.4\%), missing a class (38.9\%) and being unable to concentrate in class (42.8\%) (Table 2).

Hazardous drinkers were also significantly more likely to report second-hand harms due to other students' alcohol consumption during the last four weeks (Table 2). Almost half (44.4\%) of hazardous drinkers had taken care of another student who had drunk too much while $34.3 \%$ had study or sleep interrupted, $28.5 \%$ had been assaulted or humiliated and $22.1 \%$ experienced an unwanted sexual advance. Similarly hazardous drinkers reported significantly higher levels of witnessed harms associated with other students' drinking compared to low risk drinkers. Hazardous drinkers reported witnessing: someone "passes out" (50.5\%); a serious quarrel or argument (41\%); someone being hit, pushed or otherwise assaulted (33.7\%); and someone experience an unwanted sexual advance (23.5\%) (Table 2).

Although there was a significant difference between all alcohol expectancies for low risk and hazardous drinkers $(\mathrm{p}<0.001)$ a high proportion of all low risk and hazardous drinkers felt alcohol would make them act more sociably (78\%) and help them talk to people (76.4\%). Over $60 \%$ of student drinkers felt alcohol would enhance socialisation, risk taking and relaxation. This was in contrast to expectancies that after a few drinks of 
Table 2. Alcohol related problems experienced by hazardous and low risk drinkers due to experienced, second-hand and witnessed harms, academic problems and alcohol expectancies.

\begin{tabular}{|c|c|c|c|c|}
\hline Experienced harms $(n=1995)$ & Low risk N (\%) & Hazardous N (\%) & Total N (\%) & $\mathbf{p}$ \\
\hline Had a hangover & $692(57.8)$ & $729(91.5)$ & $1421(71.2)$ & 0.000 \\
\hline An emotional outburst & 321 (26.8) & 457 (57.3) & 778 (39) & 0.000 \\
\hline Vomiting & $486(40.6)$ & $584(73.3)$ & $1070(63.6)$ & 0.000 \\
\hline Had a heated argument & $139(11.6)$ & 315 (39.5) & $454(22.8)$ & 0.000 \\
\hline Were physically aggressive & $45(3.8)$ & $162(20.3)$ & $207(10.4)$ & 0.000 \\
\hline Had blackouts & 286 (23.9) & $567(71.1)$ & $853(42.8)$ & 0.000 \\
\hline Inability to pay bills & $19(1.6)$ & $62(7.8)$ & $81(4.1)$ & 0.000 \\
\hline Had unprotected sex & $111(9.3)$ & $275(34.5)$ & 386 (19.3) & 0.000 \\
\hline Involved in a sexual situation unhappy about at time & $57(4.8)$ & $118(14.8)$ & $175(8.8)$ & 0.000 \\
\hline Involved in a sexual encounter later regretted & $98(8.2)$ & $237(29.7)$ & $335(16.8)$ & 0.000 \\
\hline Suffered an injury & $20(1.7)$ & $74(9.3)$ & $94(4.7)$ & 0.000 \\
\hline Drove a car & $110(9.2)$ & $229(28.7)$ & $339(17)$ & 0.000 \\
\hline Passenger in a car & $133(11.1)$ & $316(39.6)$ & $449(22.5)$ & 0.000 \\
\hline Stole private or public property & $39(3.3)$ & $110(13.8)$ & $149(7.5)$ & 0.000 \\
\hline Committed an act of vandalism & $21(1.8)$ & $81(10.2)$ & $102(5.1)$ & 0.000 \\
\hline Removed or banned from a pub or club & $65(5.4)$ & $182(22.8)$ & $247(12.4)$ & 0.000 \\
\hline Were arrested & $16(1.3)$ & $18(2.3)$ & $34(1.7)$ & 0.272 \\
\hline Second-hand harm $(n=2013)$ & Low risk & High risk & Total & \\
\hline Been insulted or humiliated & $149(12.3)$ & $229(28.5)$ & $378(18.8)$ & 0.000 \\
\hline Has a serious argument or quarrel & $87(7.2)$ & $180(22.4)$ & $267(13.3)$ & 0.000 \\
\hline Been pushed, hit or otherwise assaulted & $44(3.6)$ & $109(13.6)$ & $153(7.6)$ & 0.000 \\
\hline Had your property damaged & $46(3.8)$ & $111(13.8)$ & $157(7.8)$ & 0.000 \\
\hline $\begin{array}{l}\text { Had to baby-sit or take care of another student } \\
\text { who had drunk too much }\end{array}$ & $333(27.5)$ & $357(44.4)$ & $690(34.3)$ & 0.000 \\
\hline Found vomit in halls or bathroom of residence & $83(6.9)$ & $117(14.6)$ & $200(9.9)$ & 0.000 \\
\hline Had studying or sleep interrupted & $236(19.5)$ & $275(34.2)$ & $511(25.4)$ & 0.000 \\
\hline Experienced an unwanted sexual advance & $103(8.5)$ & $178(22.1)$ & $281(14)$ & 0.000 \\
\hline Been a victim of sexual assault (including date rape) & $11(0.9)$ & $25(3.1)$ & $36(1.8)$ & 0.005 \\
\hline Been a victim of another crime on campus & $8(0.7)$ & $22(2.7)$ & $30(1.5)$ & 0.003 \\
\hline Been a victim of another crime off campus & $14(1.2)$ & $42(5.2)$ & $56(2.8)$ & 0.000 \\
\hline \multicolumn{5}{|l|}{ Witnessed harm $(n=2013)$} \\
\hline Someone being pushed, hit or otherwise assaulted & $217(17.9)$ & $271(33.7)$ & $488(24.2)$ & 0.000 \\
\hline Serious argument or quarrel & $274(22.7)$ & $330(41)$ & $604(30)$ & 0.000 \\
\hline Property damage & $136(11.2)$ & 225 (28) & 361 (17.9) & 0.000 \\
\hline Someone pass out & 349 (28.9) & 406 (50.5) & 755 (37.5) & 0.000 \\
\hline
\end{tabular}




\begin{tabular}{|c|c|c|c|c|}
\hline \multicolumn{5}{|l|}{ Continued } \\
\hline Someone you suspect had alcohol poisoning & $122(10.1)$ & $189(23.5)$ & $311(15.4)$ & 0.000 \\
\hline A sexual assault & $115(9.5)$ & $161(20)$ & $276(13.7)$ & 0.000 \\
\hline \multicolumn{5}{|l|}{ Academic problems $(n=1995)$} \\
\hline Been late for a class & $87(7.3)$ & $242(30.4)$ & $329(16.5)$ & 0.000 \\
\hline Missed a class & $129(10.8)$ & 310 (38.9) & $439(22)$ & 0.000 \\
\hline Unable to concentrate in class & $150(12.5)$ & $341(42.8)$ & $491(24.6)$ & 0.000 \\
\hline Failed to complete an assignment on time & $22(1.8)$ & $96(12)$ & $118(5.9)$ & 0.000 \\
\hline \multicolumn{5}{|l|}{ Alcohol expectancies $(n=2041)$} \\
\hline Act more sociably & $891(72.4)$ & $710(86.4)$ & $1592(78)$ & 0.000 \\
\hline Find it easier to talk to people & $880(71.5)$ & $680(83.8)$ & $1560(76.4)$ & 0.000 \\
\hline Feel calmer/more relaxed & $736(59.8)$ & $630(77.7)$ & 1366 (66.9) & 0.000 \\
\hline Enjoy sex more & 220 (17.9) & $286(35.3)$ & $506(24.8)$ & 0.000 \\
\hline Take risks & $693(56.3)$ & $630(77.7)$ & $1323(64.8)$ & 0.000 \\
\hline Be more aggressive & $239(19.4)$ & $284(35)$ & $523(25.6)$ & 0.000 \\
\hline Feel more courageous & $680(55.3)$ & 599 (73.9) & 1279 (62.7) & 0.000 \\
\hline Act loud, boisterous, noisy & 663 (53.9) & $569(70.2)$ & $1232(60.4)$ & 0.000 \\
\hline Have fun/good time & 757 (61.5) & $657(81)$ & $1414(69.3)$ & 0.000 \\
\hline
\end{tabular}

alcohol they would enjoy sex more (24.8\%) and be more aggressive (25.6\%) (Table 2).

Regression analysis found experienced alcohol related harms, academic problems, alcohol expectancies, close friends level of alcohol consumption, pre-loading in the last four weeks and level of consumption when preloading to account for a significant proposition of variance between low risk and hazardous drinking when all factors were considered $(\mathrm{p}<0.001)$ (Table 3). Number of friends who drink alcohol was a moderately significant predictor of hazardous drinking $(\mathrm{p}<0.05)$. Hazardous drinkers were approximately 1.3 and 1.1 times more likely to experience harms and academic problems respectively when compared with low risk drinkers. Students who reported hazardous drinking were approximately 1.1 times more likely to feel alcohol would increase the likelihood of "positive" and "negative" expectancies compared to low risk drinkers when all factors were considered. Hazardous drinkers were 1.6 times more likely to participate in pre-loading in the past four weeks and 1.4 times more likely to consume alcohol at higher levels when pre-loading (OR 1.4; CI 1.200 - 1.675).

\section{Discussion}

This study supports the findings of other university-based research which show high levels of hazardous drinking among young people [3] [16] [23]. Almost $40 \%$ of students in this study reported drinking at hazardous levels. An earlier 2009 study of $17-24$ years old students $(n=7237)$ at this university found $(34 \%)$ of respondents to score at hazardous levels. However the 2009 study used a combination of hazardous AUDIT and more than six standard drinks in one sitting during the last month to define hazardous drinking [7]. A 2011 Australian study $(n=603)$ found $46.6 \%$ of 18 - 24 year olds university students to drink at hazardous levels [3].

Other large studies of university students have primarily reported associations between experienced and second-hand harms and academic problems and level of alcohol consumption [2] [3] [16] [23], however this study also included alcohol expectancies. [9] measured close friend's alcohol consumption. [27] [28] measured the pre-loading and a measure of witnessed harm.

Similar to others studies, [3] males in this study were more likely to report drinking alcohol at hazardous levels (46.9\% males vs $35.2 \%$ females).However when all factors were considered gender (male/female) was not 
Table 3. Effect of predictors on hazardous compared to low risk drinking at baseline.

\begin{tabular}{ccccc}
\hline Predictor variables & Odds ratio & CI & df & p value \\
\hline Gender-female & 0.776 & $0.574-1.049$ & 1 & 0.099 \\
Experienced harms & 1.306 & $1.224-1.392$ & 1 & $0.000^{*}$ \\
Second-hand harms & 1.041 & $0.985-1.101$ & 1 & 0.150 \\
Witnessed harms & 0.991 & $0.938-1.047$ & 1 & 0.756 \\
Academic problems & 1.143 & $1.066-1.225$ & 1 & $0.000^{*}$ \\
Attitudes & 1.106 & $1.050-1.165$ & 1 & $0.000^{*}$ \\
Number of friends who drink alcohol & 1.265 & $1.079-1.483$ & 1 & $0.004^{* *}$ \\
Close friends level of alcohol consumption & 1.404 & $1.212-1.628$ & 1 & $0.000^{*}$ \\
Pre-loading in last 4 weeks & 1.640 & $1.248-2.154$ & 1 & $0.000^{*}$ \\
Level of consumption when pre-loading & 1.418 & $1.200-1.675$ & 1 & $0.000^{*}$ \\
\hline
\end{tabular}

Significant at $\mathrm{p}<0.001^{*}$; significant at $\mathrm{p}<0.05^{* *}$.

found to be a significant predictor of hazardous drinking in this study suggesting factors such as peer drinking, alcohol expectancies, experienced harms, academic problems and behaviors such as pre-loading to be more significant predictors of risky alcohol consumption.

While experienced and second-hand harms have been widely measured [2] [7] [23] [26], this study also included questions regarding witnessed harms. Although univariate analysis found hazardous drinkers to be significantly more likely to witness harms associated with other students' alcohol consumption compared to low risk drinkers, the witnessed harms score was not significant when all factors were considered suggesting interventions should consider universal strategies to address these harms. Witnessed harms such as an interpersonal or sexual assault, someone passing out and someone you suspect having alcohol poisoning pose a range of social, emotional and physical health issues. These data, along with similar findings for the experienced and secondhand harms support-the need for basic first aid and help seeking awareness in addition to comprehensive mental and physical first aid training opportunities for students.

This study found pre-loading to be common with $60.5 \%$ of low risk and hazardous drinkers reporting to pre-load at least once in the last four weeks. Pre-loading has been found to be common with one small $(\mathrm{n}=112)$ US study finding $64.3 \%$ of participants had drunk alcohol prior to attending an event or social activity in the past two weeks. The amount consumed during pre-loading sessions predicted the expectancies of consumption later in day [30]. Similarly, a larger study of young adult bar patrons in the US $(n=1040)$ found pre-loading to be common among college populations, to be similar for males and females and to be associated with intentions to drink [31]. Young university students identify the economic benefits of pre-loading prior to going to a pub or club [10]. In addition to issues related to over consumption, pre-loading introduces a range of issues including drink-driving and "street-drinking" where students may walk from their residence to campus venues.

Alcohol expectancies have been found to predict alcohol consumption among young people [9]. This study found hazardous drinkers to be significantly more likely to agree that all expectancies were more likely after a few drinks compared to low risk drinkers. Hazardous drinkers were more likely to associate alcohol to enhance socialization and inhibitions. Young drinkers have been found to associate alcohol consumption with a range of positive outcomes which have been found to predict onset and duration of drinking [9] [32] such expectancies reinforce the culture of drinking behaviors which are normalized in some university environments [1].

Given the homogeneity of peer groups [33], it is not surprising that this study, like others [12], found students who drink alcohol were most likely to have close friends who have similar drinking patterns. Peers have been found to influence positive health behavior changes [34] and should be an important focus of intervention strategies.

Harms experienced in this study were similar to other studies in New Zealand [26] and Australia [3]. Academic problems such as being late for a class, missing a class and being unable to concentrate were significantly more likely to be experienced by hazardous drinkers. Respondents in this study reported slightly lower academic 
problems compared to students in New Zealand [26]. Almost one quarter (24.6\%) of low risk and hazardous drinkers from this study reported to have been unable to concentrate in class as a result of alcohol consumption in the past four weeks compared to $40.1 \%$ of females and $40.9 \%$ of males in McGee and Kypri's study of New Zealand university students $(\mathrm{n}=1464)$ [26].

Second-hand harms such as having study or sleep interrupted, being insulted or humiliated and being involved in a serious argument or quarrel have been identified as an issue for all students, regardless of their level of alcohol consumption. Similar to other studies [5], second-hand harms were significantly $(\mathrm{p}<0.001)$ more likely to be experienced by hazardous drinkers. However as with other studies [5], low risk drinkers were also likely to experience harms. Approximately one third of students had taken care of another student who had drunk too much. Half of hazardous drinkers and over one third of all drinkers had witnessed someone pass out due to alcohol in the past four weeks.

A range of experienced, second-hand and witnessed harms associated with alcohol consumption and sexual activities were reported by students in this study. While hazardous drinkers were more likely to report sexual harms, a proportion of low risk drinkers had also participated in unprotected sex or experienced a regretted sexual encounter because of their own drinking, or had experienced or witnessed an unwanted sexual advance as a result of other students' drinking. There is a strong association between risky and regrettable sexual activity and risky alcohol consumption among young people [35] which warrants consideration when planning interventions.

Novice drivers are at risk of a range of risky driving behaviors including drink-driving [36] [37]. The high proportion of students in this study who reported to drink-drive (17\%) or drink-ride (22.5\%) reinforces the need for specific strategies targeting this issue. In comparison a New Zealand study of university students $(\mathrm{n}=1564)$ found drink-driving to be reported by $3.4 \%$ of women and $8.4 \%$ of men and drink-riding by $7 \%$ and $11.5 \%$ of women and men respectively however the reference period was over four weeks as opposed to twelve months [8].

This study has added to the current literature which highlights the harms associated with hazardous alcohol consumption among young university students [2] [7] [23] [26] by including focus an additional item relating to witnessed harms in addition to alcohol expectancies, peer behaviors and pre-loading. These data recognise the complexity of alcohol use for young people and will help inform the development of interventions.

\section{Limitations}

The cross sectional nature of this study precluded casual assumptions [29]. Females were more likely to participate in this study (62.1\%), however this is similar to other studies [38] and the disparity is not as large as another Australian university study targeting this age group (females 71\%) [3]. Selective non-response may have biased these results however levels of alcohol consumption were similar to other studies of this cohort [3] [23] The response rate for this study was low (32.2\%) however in their cross sectional study Rickwood and colleagues [3] reported a response rate of $12.9 \%$. Response rates were higher for an earlier study at this campus (55.6\%) however that study was able to recruit via letter and email and followed up non-respondents with a personalized letter and up to three emails [2]. These resources were beyond the scope of this study. Data were only collected from one university which may limit the generalizability of the results. The limitations of this study should be considered when reviewing the results.

\section{Conclusion and Implications}

These findings support the need for integrated and coordinated comprehensive interventions to address the culture associated with alcohol consumption among university students. Alcohol related harms and problems are an issue for all students, regardless of level of drinking. Interventions need to include universal strategies to reduce harms for the whole student population, in addition to implementing selective and indicated strategies to target students at higher risk. While a range of harms were experienced and witnessed by students in this study the findings highlight the need for general safety and first aid messages, inclusion of mental health strategies, in addition to a focus on drink driving and sexual negotiation. Peers play an important role in influencing behaviors of this target group. Interventions should consider strategies to enhance positive peer involvement and influence. To-date published university-based interventions have focused on specific, individually focused strategies. These findings will be used to inform the development of comprehensive strategies focusing on strategic partnerships, organizational structural change, capacity building and advocacy, media and sponsorship and training and edu- 
cation. Long term commitment is necessary to effect positive changes to the current culture of alcohol consumption among young university students.

\section{Acknowledgements}

We would like to acknowledge the participants of this study who gave their time to complete the survey, the Curtin Office for Strategy and Planning and health promotion students for help administering the survey. We gratefully acknowledge Healthway (The Western Australian Health Promotion Foundation) for funding this project.

\section{Competing Interests}

The authors declare they have no completing interests.

\section{References}

[1] Kypri, K., Cronin, M. and Wright, C.S. (2005) Do University Students Drink More Hazardously than Their Non-Student Peers? Addiction, 100, 713-717. http://dx.doi.org/10.1111/j.1360-0443.2005.01116.x

[2] Kypri, K., Hallett, J., Howat, P., McManus, A., Maycock, B., Bowe, S. and Horton, N.J. (2009) Randomized Controlled Trial of Proactive Web-Based Alcohol Screening and Brief Intervention for University Students. Archives of Internal Medicine, 169, 1508-1514. http://dx.doi.org/10.1001/archinternmed.2009.249

[3] Rickwood, D., George, A., Parker, R. and Mikhailovich, K. (2011) Harmful Alcohol Use on Campus: Impact on Young People at University. Youth Studies Australia, 30, 34-40.

[4] Glider, P., Midyett, S.J., Mills-Novoa, B., Johannessen, K. and Collins, C. (2001) Challenging the Collegiate Rite of Passage: A Campus-Wide Social Marketing Media Campaign to Reduce Binge Drinking. Journal of Drug Education, 31, 207-220. http://dx.doi.org/10.2190/U466-EPFG-Q76D-YHTQ

[5] Langley, J.D., Kyrpi, K. and Stephenson, S.C.R. (2003) Secondhand Effects of Alcohol Use among University Students: Computerised Survey. British Medical Journal, 327, 1023-1024. http://dx.doi.org/10.1136/bmj.327.7422.1023

[6] Wechsler, H., Lee, J.E., Kuo, M., Seibring, M., Nelson, T.F. and Lee, H. (2002) Trends in College Binge Drinking During a Period of Increased Prevention Efforts: Findings from 4 Harvard School of Public Health College Alcohol Study Surveys: 1993-2001. Journal of American College Health, 50, 203-217. http://dx.doi.org/10.1080/07448480209595713

[7] Hallett, J, Howat, P.M., Maycock, B.R., McManus, A., Kypri, K. and Dhaliwal, S.S. (2012) Undergraduate Student Drinking and Related Harms at an Australian University: Web-Based Survey of a Large Random Sample. BMC Public Health, 12, 37. http://dx.doi.org/10.1186/1471-2458-12-37

[8] Kypri, K. and Stephenson, S. (2005) Drink-Driving and Perceptions of Legally Permissible Alcohol Use. Traffic Injury Prevention, 6, 219-224. http://dx.doi.org/10.1080/15389580590969120

[9] Ham, L.S., Stewart, S.H., Norton, P.J. and Hope, D.A. (2005) Psychometric Assessment of the Comprehensive Effects of Alcohol Questionnaire: Comparing a Brief Version to the Original Full Scale. Journal of Psychopathology and Behavioral Assessment, 27, 141-158. http://dx.doi.org/10.1007/s10862-005-0631-9

[10] Hallett, J., McManus, A., Maycock, B.R., Smith, J. and Howat, P.M. (2014) "Excessive Drinking-An Inescapable Part of University Life?” A Focus Group Study of Australian Undergraduates. Open Journal of Preventive Medicine, 4, 616-629. http://dx.doi.org/10.4236/ojpm.2014.47071

[11] LaBrie, J.W., Hummera, J.F., Neighborsb, C. and Larimerb, M.E. (2010) Whose Opinion Matters? The Relationship between Injunctive Norms and Alcohol Consequences in College Students. Addictive Behaviors, 35, 343-349. http://dx.doi.org/10.1016/j.addbeh.2009.12.003

[12] Stappenbeck, C.A., Quinn, P.D., Wetherill, R.R. and Fromme, K. (2010) Perceived Norms for Drinking in the Transition from High School to College and beyond. Journal of Studies on Alcohol and Drugs, 71, 895-903.

[13] Roche, A.M. and Watt, K. (1999) Drinking and University Students: From Celebration to Inebriation. Drug and Alcohol Review, 18, 389-399. http://dx.doi.org/10.1080/09595239996257

[14] Kypri, K., Langley, J.D., McGee, R., Saunders, J.B. and Williams, S. (2002) High Prevalence, Persistent Hazardous Drinking among New Zealand Tertiary Students. Alcohol and Alcoholism, 37, 457-464. http://dx.doi.org/10.1093/alcalc/37.5.457

[15] Fachini, A., Aliane1, P.P., Martinez, E.Z. and Furtado, E.F. (2012) Efficacy of Brief Alcohol Screening Intervention for College Students (BASICS): A Meta-Analysis of Randomized Controlled Trials. Substance Abuse Treatment, Pre- 
vention and Policy, 7, 40. http://dx.doi.org/10.1186/1747-597X-7-40

[16] Kypri, K., Langley, J.D., Saunders, J.B., Cashell-Smith, M.L. and Herbison, P. (2008) Randomized Controlled Trial of Web-Based Alcohol Screening and Brief Intervention in Primary Care. Archives Internal Medicine, 168, 530-536. http://dx.doi.org/10.1001/archinternmed.2007.109

[17] Saunders, J.B., Aasland, O.G., Babor, T.F., De La Fuente, J.R. and Grant, M. (1993) Development of the Alcohol Use Disorders Identification Test (AUDIT): WHO Collaborative Project on Early Detection of Persons with Harmful Alcohol Consumption-II. Addiction, 88, 791-804. http://dx.doi.org/10.1111/j.1360-0443.1993.tb02093.x

[18] Moreira, M.T., Oskrochi, R. and Foxcroft, D.R. (2012) Personalised Normative Feedback for Preventing Alcohol Misuse in University Students: Solomon Three-Group Randomised Controlled Trial. PLOS One, 7, e44120. http://dx.doi.org/10.1371/journal.pone.0044120

[19] Chapman, S. and Freeman, B. (2009) Markers of the Denormalisation of Smoking and the Tobacco Industry. Tobacco Control, 17, 25-31. http://dx.doi.org/10.1136/tc.2007.021386

[20] White, V., Siahpush, M. and Bobevski1, I. (2003) How Has the Prevalence of Cigarette Smoking Changed among Australian Adults? Trends in Smoking Prevalence between 1980 and 2001. Tobacco Control, 12, ii67-ii74. http://dx.doi.org/10.1136/tc.12.suppl_2.ii67

[21] Howat, P.A., Maycock, B., Cross, D., Collins, J., Jackson, L., Burns, S. and James, R. (2003) Towards a More Unified Definition of Health Promotion. Health Promotion Journal of Australia, 14, 82-85.

[22] Stafford, J., Allsop, S. and Daube, M. (2014) From Evidence to Action: Health Promotion and Alcohol. Health Promotion Journal of Australia, 25, 8-13. http://dx.doi.org/10.1071/HE14001

[23] Hallett, J., Howat, P., McManus, A., Meng, R., Maycock, B. and Kypri, K. (2013) Academic and Personal Problems among Australian University Students Who Drink at Hazardous Levels: Web-Based Survey. Health Promotion Journal of Australia, 24, 170-177. http://dx.doi.org/10.1071/HE13094

[24] Kypri, K., Paschall, M.J., Langley, J., Baxter, J., Cashell-Smith, M. and Bourdeau, B. (2009) Drinking and AlcoholRelated Harm among New Zealand University Students: Findings from a National Web-Based Survey. Alcoholism: Clinical and Experimental Research, 33, 307-314. http://dx.doi.org/10.1111/j.1530-0277.2008.00834.x

[25] Burns, S.K., Jancey, J., Bowser, N., Comfort, J., Crawford, G., Hallett, J., et al. (2013) Moving Forward: A Cross Sectional Baseline Study of Staff and Student Attitudes towards a Totally Smoke Free University Campus. BMC Public Health, 13, 738. http://dx.doi.org/10.1186/1471-2458-13-738

[26] McGee, R. and Kypri, K. (2004) Alcohol-Related Problems Experienced by University Students in New Zealand. Australian and New Zealand Journal of Public Health, 28, 321-323. http://dx.doi.org/10.1111/j.1467-842X.2004.tb00437.x

[27] Scholte, R., Poelena, E.A.P., Willemsenb, G., Boomsmab, D.I. and Engelsa, R.C.M.E. (2008) Relative Risks of Adolescent and Young Adult Alcohol Use: The Role of Drinking Fathers, Mothers, Siblings, and Friends. Addictive Behaviors, 33, 1-14. http://dx.doi.org/10.1016/j.addbeh.2007.04.015

[28] Core Institute SIU (2000) Campus Survey of Alcohol and Other Drug Norms. Southern Illinois University, Carbondale.

[29] Portney, L.G. and Watkins, M.P. (1993) Foundations of Clinical Research: Applications to Practice. Appleton \& Lange, Connecticut.

[30] De Jong, W., DeRicco, B. and Kessel Schneider, S. (2010) Pregaming: An Exploratory Study of Strategic Drinking by College Students in Pennsylvania. Journal of American College Health, 58, 307-316. http://dx.doi.org/10.1080/07448480903380300

[31] Reed, M.B., Clappa, J.D., Weber, M., Trim, R., Lange, J. and Shillington, A.M. (2011) Predictors of Partying Prior to Bar Attendance and Subsequent BrAC. Addictive Behaviors, 36, 1341-1343. http://dx.doi.org/10.1016/j.addbeh.2011.07.029

[32] Killen, J.D., Hayward, C., Wilson, D.M., Haydel, K.F., Robinson, T.N., Taylor, C.B., et al. (1996) Predicting Onset of Drinking in a Community Sample of Adolescents: The Role of Expectancy and Temperament. Addictive Behaviors, 21, 473-480. http://dx.doi.org/10.1016/0306-4603(95)00077-1

[33] Espelage, D.L., Holt, M.K. and Henkel, R.R. (2003) Examination of Peer-Group Contextual Effects on Aggression during Early Adolescence. Child Development, 74, 205-220. http://dx.doi.org/10.1111/1467-8624.00531

[34] Burns, S.K., Cross, D.S. and Maycock, B.R. (2010) “That Could Be Me Squishing Chips on Someone’s Car.” How Friends Can Positively Influence Bullying Behaviors. The Journal of Primary Prevention, 31, 209-222. http://dx.doi.org/10.1007/s10935-010-0218-4

[35] Jepson, R.G., Harris, F.M., Platt, S. and Tannahill, C. (2010) The Effectiveness of Interventions to Change Six Health Behaviours: A Review of Reviews. BMC Public Health, 10, 538. http://dx.doi.org/10.1186/1471-2458-10-538 
[36] Vassallo, S., Smart, D., Sanson, A., Harrison, W., Harris, A., Cockfield, S. and McIntyre, A. (2007) Risky Driving among Young Australian Drivers: Trends, Precursors and Correlates. Accident Analysis and Prevention, 39, 444-458. http://dx.doi.org/10.1016/j.aap.2006.04.011

[37] Scott-Parker, B., Watson, B., King, M.J. and Hyde, M.K. (2014) “I Drove after Drinking Alcohol” and Other Risky Driving Behaviours Reported by Young Novice Drivers. Accident Analysis and Prevention, 70, 65-73. http://dx.doi.org/10.1016/j.aap.2014.03.002

[38] Bingham, C.R., Barretto, A.I., Walton, M.A., Bryant, C.M. and Shope, J.T. (2010) Efficacy of a Web-Based, Tailored, Alcohol Prevention/Intervention Program for College Students: Initial Findings. Journal of American College Health, 58, 349-356. http://dx.doi.org/10.1080/07448480903501178 
Scientific Research Publishing (SCIRP) is one of the largest Open Access journal publishers. It is currently publishing more than 200 open access, online, peer-reviewed journals covering a wide range of academic disciplines. SCIRP serves the worldwide academic communities and contributes to the progress and application of science with its publication.

Other selected journals from SCIRP are listed as below. Submit your manuscript to us via either submit@scirp.org or Online Submission Portal.
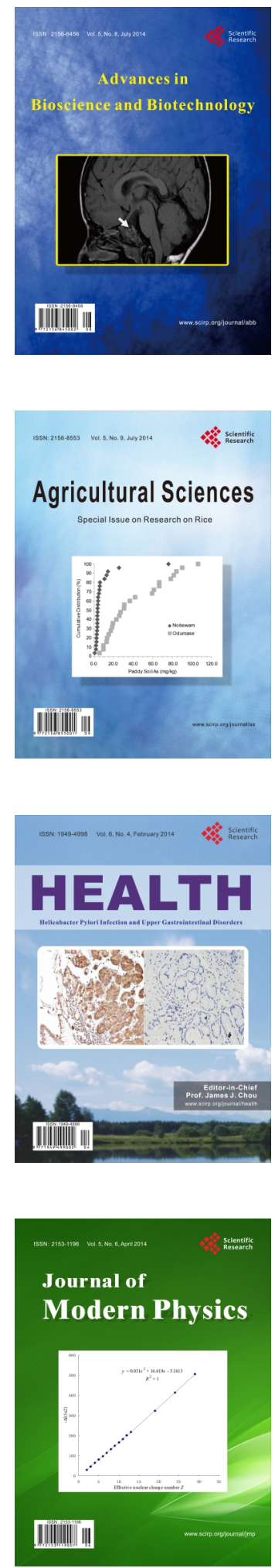
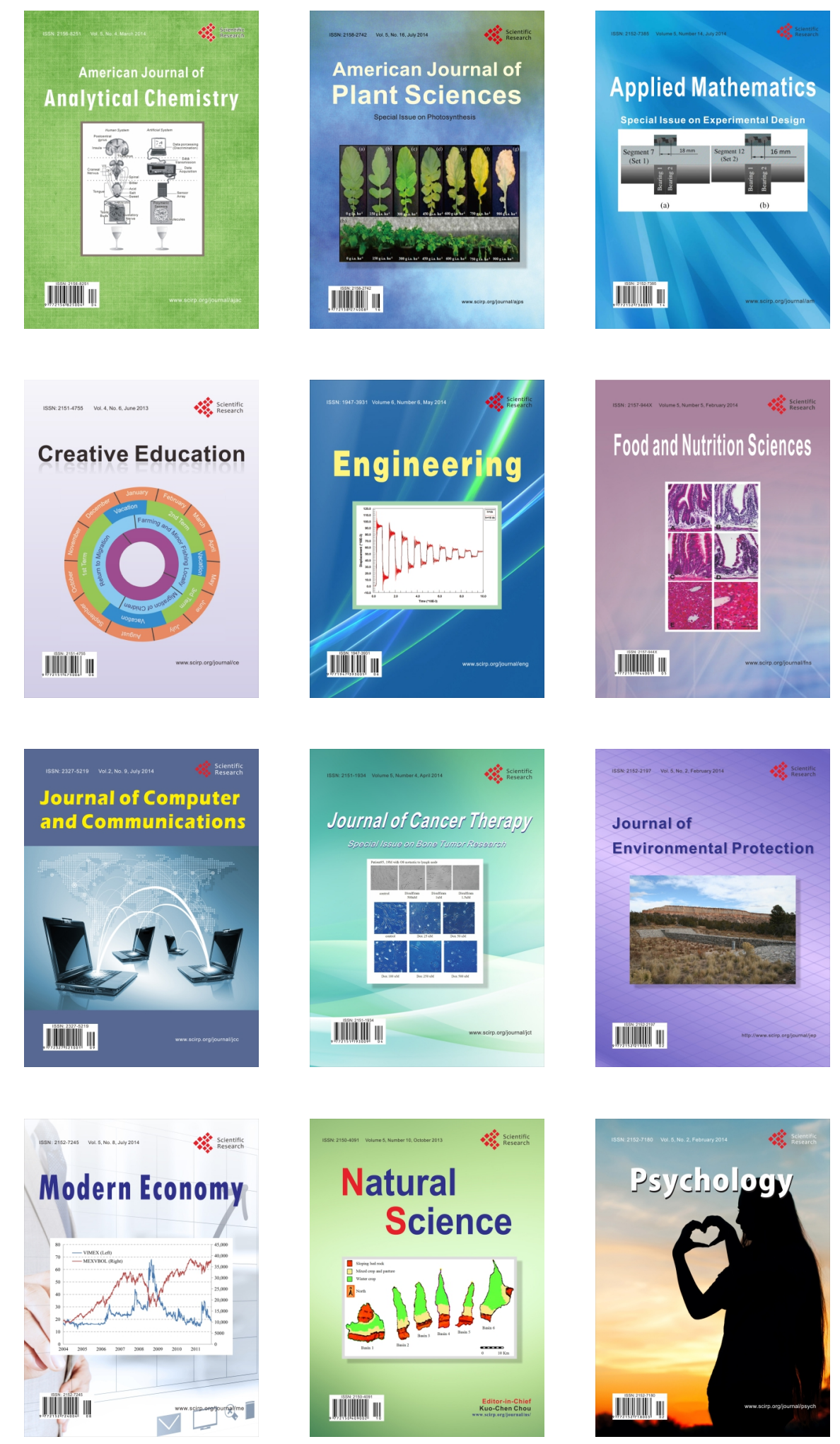